\title{
Estimation of 5-hydroxytryptamine (5-HT) level in cerebrospinal fluid of patients with intracranial or spinal lesions
}

\author{
S. S. MISRA, K. S. P. SINGH, AND K. P. BHARGAVA \\ From the Departments of Medicine and Pharmacology and Therapeutics, \\ King George's Medical College, Lucknow University, Lucknow, India
}

The presence of 5-hydroxytryptamine (5-HT, serotonin) in the cerebrospinal fluid of patients suffering from various neurological disorders has been reported by a number of investigators (Sachs, 1957; Woolley and Campbell, 1962; Snow, Lennard-Jones, Gurzon, and Stacey, 1955; Turner and Mauss, 1959; Akcasu, Akcasu, and Tumay, 1960). Singh, Misra, and Bhargava (1964, 1965) reported elevation of the 5-HT level in the cerebrospinal fluid of patients suffering from infective conditions of the central nervous system and in leprosy. Feldman, Izak, and Nelken (1957) failed to find measurable amounts of 5-HT in multiple sclerosis but raised levels in the cerebrospinal fluid were detected in 19 cases of cerebral vascular accident by Southren and Christoff (1962).

\section{METHODS AND MATERIAL}

Cerebrospinal fluid was obtained from in-patients. Banana, tomato, and pineapple were eliminated from the diet of the patients and no tranquillizers (such as reserpine), hypnotics (such as barbiturates), or analgesics were given.

Samples of cerebrospinal fluid from 48 healthy persons served as controls, and were the same as those reported earlier (Singh et al., 1964).

Cases of cerebral vascular accident were diagnosed on history, clinical examination, cytobiochemical examination of the cerebrospinal fluid, and funduscopy in all cases. Eight cases of recent origin were examined within 24 hours of the episode while six cases came to the hospital with a history of three weeks and these were grouped as 'old cases'. In 11 cases of paraplegia of sudden onset eight were of traumatic origin and three of possibly tubercular origin. In three cases of 'tubercular' paraplegia evidence of tuberculosis elsewhere in the body was present but no organism could be demonstrated on culture or guinea-pig inoculation of cerebrospinal fluid and caseous material obtained at operation. Eleven cases of traumatic quadriplegia of sudden onset were also studied for the presence of 5-HT in the cerebrospinal fluid.
Only non-traumatic samples of cerebrospinal fluid were obtained by lumbar puncture in autoclaved glass stoppered bottles with $0.5 \mathrm{mg}$. per millilitre of ascorbic acid as preservative and stored at $10^{\circ} \mathrm{C}$. until the estimation was done. Uteri for bioassay were obtained from rats (weight 60-80 g.) pretreated with intraperitoneal injection of stilboestrol $(250 \mu \mathrm{g}$. $/ 100 \mathrm{~g}$. daily for three consecutive days). The tissue was suspended in a $10 \mathrm{ml}$. bath containing de Jalon's fluid (composition: $\mathrm{NaCl} 9.0 \mathrm{~g}$, $\mathrm{KCl} 0.42$ g., $\mathrm{CaCl}_{2} 0.06$ g., dextrose 0.5 g., $\mathrm{NaHCO}_{3}$ $0.5 \mathrm{~g}$., and atropine sulphate $10 \mu \mathrm{g}$. in 1 litre doubledistilled water) kept at a temperature of $25^{\circ} \mathrm{C}$. A specially designed straw-lever was employed to record the contractions of the uterus on smoked kymograph paper. The sensitivity of this method was higher than that of the method used by Gaddum and Hameed (1954). A volume of 1 to $4 \mathrm{ml}$. of cerebrospinal fluid was added to the bath to detect the presence of 5-HT. Specific block of the 5-HT response was obtained with $40 \mu \mathrm{g}$. $/ \mathrm{ml}$. of 2-bromolysergic acid diethylamide (BOL-148).

Two-dimensional ascending chromatography was done according to the method of Jensen (1962) using $100 \mathrm{ml}$. pooled samples of cerebrospinal fluid from cases of cerebral vascular accident. The chromatographic spots of indoles were detected by spraying with Ehrlich's reagent. Ten gram $p$-dimethylaminobenzaldehyde was dissolved in $100 \mathrm{ml}$. concentrated hydrochloric acid and immediately before use $5 \mathrm{ml}$. of this solution was mixed with $20 \mathrm{ml}$. acetone and sprayed on the paper to give the characteristic colour reaction. The $\mathrm{Rf}$ values were checked by running a control chromatogram of reference compounds (tryptophan, tryptamine, and 5-HT). For further confirmation of 5-HT, the corresponding indole spots from another unsprayed chromatogram were eluted and tested on the rat uterus. The spot was identified by checking the $\mathrm{Rf}$ value and marked off by tracing from a sprayed chromatogram. Specific block with BOL-148 confirmed the presence of 5-HT.

\section{RESULTS}

The results of the study are summarized in Table I. The mean control value of 5-HT in normal human cerebrospinal fluid was $10.4 \times 10^{-4} \mu \mathrm{g}$. $/ \mathrm{ml}$. A 
TABLE I

\begin{tabular}{|c|c|c|c|c|c|}
\hline \multirow[b]{2}{*}{$\begin{array}{l}\text { Subject } \\
\text { No. }\end{array}$} & \multicolumn{4}{|c|}{ SUMMARY OF RESULTS } & \multirow[b]{2}{*}{$\begin{array}{l}P \\
\text { Value }\end{array}$} \\
\hline & Type of Case & $\begin{array}{l}\text { No. of } \\
\text { Cases }\end{array}$ & $\begin{array}{l}\text { Mean } \\
\text { Value } \\
\text { of } 5-H T \\
\left(10^{-1}\right. \\
\mu g . / \mathrm{ml} .)\end{array}$ & $\begin{array}{l}\text { Mean } \\
\text { S.E. } \\
\pm\end{array}$ & \\
\hline $\begin{array}{l}1 \\
2\end{array}$ & $\begin{array}{l}\text { Control } \\
\text { Cerebral vascular } \\
\text { accident }\end{array}$ & 48 & $10 \cdot 38$ & $1 \cdot 80$ & \\
\hline & $\begin{array}{l}\text { Recent } \\
\text { Old }\end{array}$ & $\begin{array}{l}8 \\
6\end{array}$ & $\begin{array}{r}233 \cdot 30 \\
15 \cdot 80\end{array}$ & $\begin{array}{l}1.05 \\
2.07\end{array}$ & $\begin{array}{l}<0.001 \\
-0.05\end{array}$ \\
\hline $\begin{array}{l}3 \\
4\end{array}$ & $\begin{array}{l}\text { Quadriplegia (recent) } \\
\text { Paraplegia (recent) }\end{array}$ & $\begin{array}{l}11 \\
11\end{array}$ & $\begin{array}{l}60 \cdot 10 \\
50 \cdot 4\end{array}$ & $\begin{array}{l}3 \cdot 3 \\
7 \cdot 80\end{array}$ & $\begin{array}{l}-0.05 \\
<0.001\end{array}$ \\
\hline
\end{tabular}

significantly raised level of 5-HT was found in all subjects of recent cerebral vascular accidents, paraplegia, and quadriplegia of sudden onset. However, 5-HT levels were not significantly elevated in the cerebrospinal fluid obtained from old cases of cerebral vascular accidents.

Results of chromatographic separation of indoles in cerebrospinal fluid are shown in Table II. Tryptophan, tryptamine, and 5-HT were detected in pooled samples of cerebrospinal fluid obtained from cases of cerebrovascular accident of recent origin.

\section{TABLE II}

CHROMATOGRAPHIC IDENTIFICATION OF INDOLES IN $100 \mathrm{ml}$. POOLED SAMPLES OF CEREBROSPINAL FLUID

\begin{tabular}{lllll} 
Type of Case & $\begin{array}{l}\text { Trypto- } \\
\text { phan }\end{array}$ & $\begin{array}{l}\text { Trypta- } \\
\text { mine }\end{array}$ & $5-H T$ & $5-H I A A$ \\
\hline $\begin{array}{l}\text { Cerebral vascular } \\
\text { accidents (4 pools) }\end{array}$ & $(4)+$ & $(4)+$ & $(4)+$ & -
\end{tabular}

The chromatographic spots of the indoles from an unsprayed chromatogram were cut out, eluted, and tested on the rat uterus. Only the elute of the 5-HT spot produced the characteristic response which was blocked by 2-bromolysergic acid diethylamide (BOL-148).

\section{DISCUSSION}

Significantly high levels of 5-HT in cerebrospinal fluid were obtained in samples from cases of cerebral vascular accident of recent origin, and raised levels have also been reported in cases of recent cerebral vascular accident by Southren and Christoff (1962). These investigators employed the spectrophotofluorometric method to estimate 5-HT in the cerebrospinal fluid. The chemical method is much less sensitive than the biological method and hence they could not detect 5-HT in samples from old cases.

From the present study it is significant to note that the level of 5-HT in the cerebrospinal fluid was higher when the lesion was intracranial. Furthermore in the cases of quadriplegia (lesion between $\mathrm{C}_{1}-\mathrm{C}_{4}$ ) the
5-HT content of cerebrospinal fluid was higher than in cases of paraplegia (lesion between $L_{1}-L_{2}$ ). In an experimental study Carlsson, Magnusson, and Rosengren (1963) reported higher levels of 5-HT in the substance of the cord above the transection at the second thoracic vertebra than below this level.

Significantly higher levels of 5-HT were found in cases of recent catastrophe. It appears that the elevated level tends to return gradually to the control level as the acute reaction subsides. The practical significance of the elevated 5-HT level in cerebrospinal fluid cannot be stated. It may be the manifestation of a non-specific defence reaction consequent on trauma and ischaemia.

In the chromatographic studies tryptophan, tryptamine, and 5-HT were detectable in the cerebrospinal fluid of cases with intracranial lesions and the presence of 5-HT was further confirmed by testing the elute of the 5-HT spot.

\section{SUMMARY .}

The results of the present study show the presence of significantly elevated 5-HT levels in cerebrospinal fluid obtained from recent cases of cerebral vascularo accidents, quadriplegia, and paraplegia. In old cases of cerebrovascular accident the level of 5-HT wasi comparable to that in the control.

The levels of 5-HT in the cerebrospinal fluid of patients with intracranial lesions were higher than those in cerebrospinal fluid obtained from cases o spinal lesions.

In pooled samples of cerebrospinal fluid tryptophan and tryptamine and 5-HT were detected by chromatography.

The authors wish to express their thanks to Professor R. V. Singh for providing financial assistance from the funds of the University Research Grant. Grateful acknowledgment is made to Professor P. N. Tandon, of the Neurological Unit, and Dr. M. K. Goel, of the Orthopaedic Department of King George's Medical College, Lucknow, for facilities to study their patients. Our thanks are also due to the Indian Council of Medical Research for the award of a post-doctoral research fellowship to one of us (K.S.P.S.) and to M/S Sandoz (India) for the supply of 5-hydroxytryptamine and 2-bromo-lysergic acid diethylamide (BOL-148).

\section{REFERENCES}

Akcasu, A., Akcasu, K., and Tumay, S. B. (1960). 5-hydroxytryptamine in cerebrospinal fluid. Nature (Lond.), 187, 324.

Carlsson, A., Magnusson, T., and Rosengren, E. (1963). 5-hydroxytryptamine of the spinal cord normally and after transection. Experientia (Basel), 19, 359.

Feldman, S., Izak, G., and Nelken, D. (1957). Blood coagulation studies and serotonin determinations in serum and cerebrospinal fluid in multiple sclerosis. Acta. psychiat scand., 32, $37-49$.

Gaddum, J. H., and Hameed, K. A. (195^). Drugs which antagonize 5-hydroxytryptamine. Brit. J. Pharmacol., 9, 240-248. 
Jensen. K. (1962). Paper chromatographic determination of indoles in human cerebrospinal fluid. Acta. neurol. scand., 38, 278-284.

Sachs, E. Jr. (1957). Acetylcholine and serotonin in the spinal fluid. J. Neurosurg., 14, 22-27.

Singh, K. S. P., Misra, S. S., and Bhargava, K. P. (1964). 5-hydroxytryptamine (5-HT) content of cerebrospinal fluid in infective conditions of the central nervous system. J. Lab. clin. Med., 64, 801-807.

(1965). 5-hydroxytryptamine content of cerebrospinal fluid in leprosy. Nature (Lond.), 206, 206-207.

Snow, P. J. D., Lennard-Jones, J. E., Gurzon, G., and Stacey. R. S.
(1955). Humoral effects of Metastasising carcinoid tuomurs. Lancet, 2, 1004-1009.

Southren, A. L., and Christoff, N. (1962). Cerebrospinal fluid serotonin in brain tumor and other neurological disorders determined by a spectrophotofluorometric technique. J. La's. clin. Med., 59, 320-326.

Turner, W. J., and Mauss, E. A. (1959). Serotonin and acetylcholine in human ventricular and spinal fluids. A.M.A. Arch. gen. Psychiat., 1, 646-650.

Woolley, D. W., and Campbell, N. K. (1962). Exploration of the central nervous system serotonin in humans. Ann. N.Y. Acad. Sci., 96, 108-117. 